\title{
LUT
}

Lappeenranta

University of Technology

\section{Modeling the effects of the new Russian capacity mechanism on renewable energy investments}

Kozlova Mariia, Collan Mikael
This is an Pre-print
version of an article
published by Elsevier
in Energy Policy

DOI: $10.1016 /$ j.enpol.2016.05.014

Copyright of the original publication: (c) Elsevier 2016

Please cite the publication as follows:

Kozlova, M., Collan, M. (2016). Modeling the effects of the new Russian capacity mechanism on renewable energy investments. Energy Policy, Vol 95, Issue 1. p.350-360. DOI: 10.1016/j. enpol.2016.05.014

This is a parallel published version of an original article. This version can differ from the original published article. 


\title{
Modeling the effects of the new Russian capacity mechanism on renewable energy investments
}

\author{
Mariia Kozlova ${ }^{\mathrm{a}}$ and Mikael Collan ${ }^{\mathrm{b}}$, \\ ${ }^{a, b}$ School of Business and Management, Lappeenranta University of Technology, \\ Skinnarilankatu 34, 53851 Lappeenranta, Finland \\ ${ }^{a}$ corresponding author mariia.kozlova@lut.fi
}

\begin{abstract}
Russian renewable energy policy, introduced in May 2013, is a capacity mechanism-based approach to support wind, solar, and small hydro power development in Russia. This paper explores the effect of the new mechanism on the profitability of new renewable energy investments with a numerical example. The sensitivity of project profitability to selected factors is studied and the results are compared ceteris paribus to results from a generic feed-in premium case. Furthermore, the paper gives a complete and detailed presentation of the capacity price calculation procedure tied to the support mechanism.
\end{abstract}

The results show that the new Russian renewable energy capacity mechanism offers a significant risk reduction to the investor in the form of dampening the sensitivity to external market factors. At the same time it shields the energy market system from excessive burden of renewable energy support. Even if the complexity of the method is a clear drawback to the detailed understanding of how the mechanism works, the design of the incentive policy could be an appealing alternative also for other emerging economies.

Keywords-Russia, Capacity mechanism, renewable energy policy

\footnotetext{
Abbreviations

ATS - Administrator of Trading System

CAPEX - Capital expenditures

CIA - Central Intelligence Agency

CPI - Consumer price index

DPM - Agreements for the delivery of capacity

FiT - Feed-in tariffs

NPV - Net present value

OJSC - Open joint-stock company

OPEX - Operational expenditures

RAO UES - Unified Energy System of Russia

RE - Renewable energy

RPS - Renewable portfolio standard

$\mathrm{SO}$ - System Operator
} 


\section{Highlights}

- New Russian RE investment incentive mechanism is presented in detail;

- Effect of the mechanism on RE investment profitability is numerically illustrated;

- Sensitivity of project profitability to selected variables is studied;

- Sensitivity results are compared to results under a generic feed-in premium;

- The mechanism is shown to reduce market-related risks of RE investments.

\section{Introduction}

This paper studies the effect that the recently introduced Russian renewable energy (RE) incentive policy for the wholesale electricity market has on new renewable energy project investment profitability. This policy is an extension of the Russian pre-existing capacity trade mechanism and it is considerably different from other renewable energy support schemes implemented worldwide. We present the Russian RE incentive policy in detail, show how it affects RE investment profitability, and analyze the importance of the main variables of the policy mechanism on investment profitability.

The Russian RE investment support policy has been launched based on the background of the threat of global warming and the exhaustion of non-renewable energy resources that have caused the Russian government, in unison with many other governments around the world, to act in favor of RE investments. Renewable energy adoption and its diffusion that is taking place worldwide owes partly to the introduction of RE supporting mechanisms and this is why support mechanism design is a key factor in determining how much new RE power generation investments are started, i.e., the support mechanisms are an important determinant in how well RE supporting policies fair in terms of efficiency (del Río and Cerdá, 2014). It is important to note in this vein that RE policy designs differ from country to country (International Energy Agency and International Renewable Energy Agency, 2014). Most of the RE support schemes used can be grouped into three system design types that are feed-in tariffs (FIT), tender- 
or auction-based term-based tariff systems, and renewable energy portfolio standards (RPS), or quota systems (REN21, 2015). The feed-in-tariff designs introduce a guaranteed (often fixed) special price, or a price premium, for generated RE electricity and there is evidence to suggest that these have been successful in incentivizing RE deployment (Fais et al., 2014; Lund, 2007; Maurer and Barroso, 2011). There is evidence to suggest that feed-in-tariffs may be a more expensive policy alternative for the "tax payer", than renewable energy portfolio standards, where pricing of generated RE electricity is typically set by the markets (Maurer and Barroso, 2011; Azuela and Barroso, 2012). Auction-based schemes attempt to find a balance between set (fixed) and the market pricing, by creating a market-based price for term contracts that then provide a fixed term price (del Río and Linares, 2014; Maurer and Barroso, 2011).

Developed countries have played a pioneering role in RE deployment, but for the last years, emerging economies show higher growth in new RE investments (Frankfurt School UNEP Collaborating Centre and Bloomberg New Energy Finance, 2015). Indeed, recent studies report empirical evidence of positive causality between RE consumption and economic growth in different parts of the world (Apergis and Payne, 2010; Apergis and Payne, 2011; Salim and Rafiq, 2012). Designing RE support policies in emerging economies seems to be a task that is challenged by many potential obstacles, e.g., including political and regulatory risks, typically higher market sensitivity to shocks, and a limited access to financing (Timilsina et al., 2012; Pegels, 2010; Beck and Martinot, 2004). Furthermore, difficulty to recruit human resources with the needed know-how and poor information and documentation availability may also cause hardship for RE support system design projects in emerging economies (International Finance Corporation, 2011). Under these circumstances, emerging economies have most often resorted to adopting RE support schemes that are already in place elsewhere, by perhaps slightly adapting them for the local circumstances and/or by integrating components from different already-existing schemes to the local pre-existing systems (REN21, 2015).

Feed-in tariffs have been the "system of choice" for the majority of developing countries that have adopted a RE support system and they have spread particularly to Asian and to African countries. Some 
emerging economies have adopted auction-based RE support schemes, especially countries in Latin and in Central America. Renewable energy portfolio standards that typically allocate more risks to the investors, appear not to have become very popular among the developing countries (International Energy Agency and International Renewable Energy Agency, 2014; REN21, 2015). In response to policy failures and deficiencies in local circumstances, many developing countries have moved from one type of RE supporting mechanism to another, sometimes leaving the first initiated system in force for specific RE segments. Examples of such "policy migration" include, e.g., Brazil's shift from feed-in-tariffs to an auction-based system, China's move from auctions to FIT followed by a focused re-introduction of auctions for particular technology types, and the Indian launch of auctions on top of a pre-existing FIT system and RE certificate markets (Azuela and Barroso, 2012).

Contrary to the strategy of many other developing countries to adopt pre-existing RE policy instruments, Russia has recently introduced a new and unique design for a RE support system that is based on capacity remuneration. The foundation of the new RE capacity mechanism is the pre-existing Russian capacity trade mechanism for conventional electricity production that tries to ensure the sustainability and smooth functioning of the Russian energy system. Adopted now for renewable energy support, the Russian RE support mechanism neither guarantees a particular price, nor allows the price to be fully formed by the markets. Instead the Russian mechanism is a set of specific remuneration calculation procedures that try to ensure a set fixed return on RE investments that is able to adapt to changing market conditions throughout a (support) contract term. The contracts are auctioned. Capacity remuneration approaches have also been implemented elsewhere in the world to enhance the reliability of electricity markets (Tennbakk et al., 2013; Hobbs et al., 2007; Held and Voss, 2013), but never before have they been adopted to support renewable energy investment.

Information available about the Russian renewable energy policy is rather limited on the international arena, because the original legislative procedures and capacity pricing instructions are publicly available only in the Russian language (Government of Russian Federation, 2013a; Government of Russian 
Federation, 2013b; Government of Russian Federation, 2015). The policy has been previously descriptively analyzed in English by the International Finance Corporation (IFC) (International Finance Corporation, 2013) in a way that is sufficient for obtaining a preliminary perception of the RE support mechanism, but not detailed enough for a full understanding of its effects on renewable energy investment deployment. In the academic literature, Russian renewable energy policy in general has received some attention prior to the introduction of the capacity mechanism, e.g., see (Martinot, 1998; Martinot, 1999; Zhang et al., 2011). In addition, the prospects of renewable energy development on the regional level and in the remote areas of Russia have been previously studied (Boute, 2013; Boute, 2016).

Literature that concentrates on the capacity mechanism, which is the main scheme to support RE in Russia and the only scheme available within the wholesale market of electricity is very limited. Anatole Boute of the IFC (2012) studies the mechanism based of a legislative act draft available at the time of his writing, the paper is positive about the ability of the Russian (then planned) scheme to create appropriate incentives for new RE investments. The final details and a detailed presentation of the final remuneration calculations are not included for the obvious reasons. Vasileva and others (Vasileva et al., (2015) have analyzed the RE capacity mechanism from a different perspective, modeling its possible impact on the electricity and the capacity prices on the Russian energy market, their results suggest only minor influence. Existing business and academic literature in English on the Russian RE support mechanism is fragmentary and does not fully present the remuneration logic of the said mechanism, the effects of the mechanism on RE investment profitability, and any consecutive implications for investors and policymakers have so far not been comprehensively analyzed.

In this vein, and in order to fill the observed research gap with regards to the Russian RE support system, this paper: i) describes the Russian RE support system and puts it in an international context; ii) numerically illustrates and analyzes the effect of how the said system affects the profitability of RE investments in Russia - the results shed new light on how the key policy features of the mechanism affect RE investment profitability, and iii) uncovers insights on policy implications for investors and for the 
Russian energy market system as a whole.

Furthermore, the paper presents, as an appendix, a detailed description of the Russian capacity pricing mechanism for the wholesale market RE in English - this is to clarify in fine grain the underlying Russian system, and while the presentation is a close reproduction of the relevant Russian laws in English and as such are not a scientific contribution at all, it is to the best of our knowledge among the first such presentations in English.

In the following section, we introduce the Russian electricity market in general and the capacity market in detail. This is followed by a description of the new renewable energy capacity mechanism, of how it is applied, and a presentation of a calculation model that is built for the purpose of analyzing the mechanism. Then a presentation of the results obtained with the model and from a sensitivity analysis performed follows. For the purposes of comparison, the model and the sensitivity analysis results are compared to results obtained from a stylized feed-in tariff mechanism model to highlight the differences between the Russian RE support mechanism and the most widely to the emerging economies spread FIT mechanism. The paper is closed with a discussion and conclusions.

\section{Russian wholesale power market and the new capacity mechanism for RE investments}

According to the CIA World Factbook Russia is ranked fourth in electricity production after China, the US, and the EU (Central Intelligence Agency, 2014). As of 2012, the total installed electricity generation capacity in Russia was 223 GW. In 2012, more than 1000 TWh of electricity was produced, thereof more than $60 \%$ by thermal power stations. Nuclear, and hydropower plants both accounted for approximately $15 \%$ of the total power production. Renewable energy sources accounted only for about $1 \%$ of the total electricity production (which mostly constitutes of expensive diesel generation substitution in remote areas, with no access to the grid). $98.5 \%$ of the produced electricity was consumed in Russia and the rest exported (Russian Ministry of Energy, 2013). Electricity consumption in Russia has been constantly 
growing at an average rate of $2 \%$ per year, since the year 2000 (data from the World Bank World Development Indicators Database), which is roughly the equivalent of $8 \mathrm{GW}$ of new installed capacity each year.

There are two commodities in the Russian electricity markets, electricity and capacity. Electricity is traded through bilateral contracts in a day-ahead market and in an intra-day balancing market. Bilateral contracts allow electricity buyers and producers to negotiate price, quantity, and supply duration directly with each other, and independently of the prevalent market conditions. The day-ahead-market is a wholesale electricity market for trades that are made a day before the actual delivery. The trade is organized in two steps: first, one week before delivery, power generators submit technical information to the power system operator OJSC "System Operator of the Unified Power System" (SO) and it forecasts the consumption and selects enough production units (by the power generators) to cover it. Second, one day before delivery, power generators selected in the first step submit price offers to the trading operator (OJSC) "Trading System Administrator" (ATS) that then selects the best offers, based on the price order (NP Market Council, 2012).

The clearing price that all power generators receive for the electricity is set at the most expensive price of the selected offers. Due to imperfect transmission capacity between some areas, power generator selection and price definition are performed separately. Overall, there are about 8000 nodes (areas) in the Russian power system that are aggregated into two price zones, on the grounds of the prevailing energy generation source. The market imbalance, e.g., power excess or deficit, is regulated through the intra-day, or balancing market, where the selection of the generators is carried out by the SO. A non-profit partnership (NP) Market Council is responsible for developing the regulatory framework and for controlling compliance with the market rules. (NP Market Council, 2012)

Capacity trade is arranged differently for existing and for the planned generation (Gore et al., 2012; Boute, 2012). Existing generation facilities are subject to market-based selection. They submit their bids 
to competitive capacity auctions, where the Administrator of Trading System (ATS) selects the cheapest offers until the point, where the required capacity is filled for a year ahead period. The required capacity is defined by the System Operator (SO). Some other types of capacity compensation also exist in the Russian system, e.g., see (Gore et al., 2012; Kuleshov et al., 2012; NP Market Council, 2012), but these are left outside the scope of this paper.

New power generation projects that are related to the "historical" centralized investment plans are entitled to long-term regulated capacity agreements (Boute, 2015). The capacity price within such agreements is calculated for each project in accordance with the procedure defined by the legislation that is designed to cover investment costs plus some return (described in the next subsection).

The demand-side capacity price is defined as a weighted average of all supply-side capacity prices, in particular of the prices within the long-term agreements for new power generation projects and prices resulting from auctions for the existing power generation. Thus, capacity buyers automatically cover all paid capacity in the market, regardless of its source (Gore and Viljainen, 2014).

Participation in the wholesale electricity and capacity markets is obligatory for power generators with more than $25 \mathrm{MW}$ installed capacity. Power plants with capacities between 5 and $25 \mathrm{MW}$ may choose, whether they want to participate in the wholesale, or in the retail market. The capacity mechanism discussed in the next section is applicable only to the wholesale market.

\subsection{The Russian capacity mechanism for conventional energy}

The Russian capacity trade system originates from the privatization of the former quasi-monopolist 'Unified Energy System of Russia' (RAO UES) that until 2008 was the owner and the controller of the majority of electricity generation, transmission, distribution facilities, and the selling process in the Russian Federation. Investors who purchased RAO UES assets had to commit to the long-term, regulated 
power delivery contracts (and investments to back these up) and they were obliged to maintain a set minimum electricity production capacity, in order to ensure the reliability of the Russian electricity system (Boute, 2012). These contracts are called "Agreements for the Delivery of Capacity" (or "DPM" in Russian) and they are regulated by several Russian national laws (Government of the Russian Federation, 2010a; Government of the Russian Federation, 2010b).

Project selection is carried out within annual auctions, where capital cost level is a competing criterion, meaning that the less expensive installations are chosen first. Power generators that win DPM at auctions are obliged, first of all, to construct and to commission a power plant in accordance with what is agreed in the contracted schedule and secondly, to be available to produce electricity thereafter and to follow the dispatching orders of the SO, in order to contribute to maintaining a balance in the network (International Finance Corporation, 2013; Government of the Russian Federation, 2010b). Violations of these obligations are punishable with fees set by the NP Market Council. With these conditions, the power generators are compensated for their capacity within the DPM term.

The capacity price is a subject to periodic adjustments that are based on changing market conditions. This is to ensure (guarantee) the coverage of the project investment cost and the operational costs of the power producer. Computed by the ATS, the capacity payments are paid to the producers monthly. This capacity agreement mechanism is meant to allow for easy access to the markets for new generation facilities that provide continuous electricity supply and that enhance the reliability of the supply of electricity on the long run. The aim of the capacity payments under a DPM is to assure a low-risk return for the energy investors. 
The variable factors in the capacity price calculation for conventional energy are the rate of return and the rate of inflation. In addition, twice during the contract duration the capacity price is adjusted, based on the changes in the electricity prices. Determining the capacity price for conventional energy sources consists of the following four steps (Government of the Russian Federation, 2010a):

Step 1. Defining a "guaranteed rate of return" reflecting changes in the local risk-free rate;

Step 2. Calculating an "expense share" to be covered by capacity revenues, to reflect the share of revenues from electricity sales;

Step 3. Computing a "capacity price component" as a sum of a variable rate annuity of project capital costs and operating expenses (multiplied by the expense share);

Step 4. Calculating the "capacity price" by adding expected property tax expenses multiplied by the expense share to the capacity price component.

The capacity price is calculated annually separately for each month of the following year. Conventional energy types applicable for the capacity mechanism are thermal power (coal, gas), hydro, and nuclear power (the last two have longer than ten-year agreement durations). The details of the capacity price calculation are presented in detail in Appendix 1 .

\subsection{The new Russian capacity mechanism for $R E$ investments}

In addition to the "old" capacity mechanism described above, available for conventional power generation investments, Russia has since May 2013 instituted an extended "RE capacity mechanism" to accommodate for investments into wind, solar, and small hydro power (less than $25 \mathrm{MW}$ ) (Government of Russian Federation, 2015; Government of Russian Federation, 2013a; Government of Russian Federation, 2013b). Using a RE capacity mechanism to incentivize the naturally variable RE production may seem un-intuitive, as capacity mechanisms are commonly and typically used for conventional energy production. In fact, if a capacity based incentive mechanism intended for RE investments is not designed well, the outcome may be what is called the "steel-in the ground" effect (Boute, 2012): capacity is 
installed, but not actually used to generate power. The Russian RE capacity mechanism is very different from the RE support and capacity mechanisms used in other countries (International Finance Corporation, 2013).

The RE capacity mechanism includes a number of specific differences from the capacity mechanism for conventional energy. The most prominent differences are:

- The inclusion of the capacity factor (ratio between the produced electricity output over a given time period and a theoretical maximum output) into the remuneration calculation, in order to reflect electricity production performance from variable-output RE power generation;

- A local content requirement (the obligation to use a given share of nationally produced equipment and services) (Government of Russian Federation, 2013a);

Reflecting the changing foreign currency exchange rate in the capacity price calculation by correcting the 'foreign' part of project capital expenses against the changes in the ruble exchange rate to the US dollar and to the euro during the project investment phase (this rule was introduced after the start the system, see (Government of Russian Federation, 2015));

The non-fixed expense share. Changes in market conditions and in the capital cost trend of RE projects are updated and incorporated into it (Government of Russian Federation, 2013a);

- The dismissal of the requirement to follow SO's dispatching orders, except for the obligation to interrupt electricity production at the demand of the SO (Government of Russian Federation, 2013a). Violations to the rule carry a $25 \%$ fee of the monthly capacity price (NP Market Council, 2013).

The rules are furthermore adapted to the special features of RE investments, such as the fact that wind power cannot be produced, when there is not wind, or that solar power cannot be produced with no or very low irradiation.

With the above differences, the RE capacity price is calculated with the same general logic as the capacity price for conventional energy sources (Government of Russian Federation, 2015; Government of Russian 
Federation, 2013a; Government of Russian Federation, 2013b). The RE capacity price calculation can be expressed shortly in four steps as follows:

Step 1. The guaranteed RE rate of return is defined, it stands at a level of $14 \%$ for projects auctioned before 2016 and at $12 \%$ for the rest, similarly corrected to the change in national risk-free rate;

Step 2. The RE expense share is calculated as a function of the variable electricity prices, the local risk-free rate, the inflation, and the capital costs of earlier project bids (technology-wise);

Step 3. Computing the RE capacity price component is calculated as a sum of a variable rate annuity of project capital costs and operating expenses (multiplied by the expense share) with the following additions and/or changes:

- The capital cost level taken into consideration is not fixed, as it is for conventional energy, but takes values of project specific planned costs (lower remuneration for lower planned costs). Here one must remember that the project capital costs are what determines the success in the initial auction and their upper limit is fixed, see Appendix 2, Table IV.

- The capital cost level is adjusted by the localization coefficient, see Appendix 2, Table VI. After the investment is built and ready, there is a qualification procedure that verifies the achievement / non-achievement of the local content requirement. If localization is not fulfilled, the coefficient substantially decreases the CAPEX level used in the calculation of the incentive, and consequently the capacity price that is in effect for the duration of the capacity agreement.

- Exchange rate movements are taken into account to adjust 'foreign' share of capital expenses.

Step 4. The RE capacity price, is calculated by adding expected property tax expenses multiplied by the expense share to the capacity price component, but in contrast to conventional energy capacity price calculation, is corrected by a so-called "load coefficient" that reflects electricity production performance of the project (project specific). The load coefficient is in place to ensure the motivation for electricity production and to prevent the 'steel-in the ground' effect. If the 
achieved annual average capacity factor is lower than the set norm one the remuneration will be substantially reduced for the year ahead, see Appendix 2, Table VII. Overall, three separate RE capacity price levels are defined as a result of the electricity production performance: "full level", when the actual capacity factor is more than $75 \%$ of the norm one, " $80 \%$ level", when the actual capacity factor is more than 50\%, and "zero" remuneration otherwise.

The "default" or normative capacity factor values are separately calculated and set for each RE technology. The normative capacity factor of $27 \%$ that is set for wind farms, means approximately $7 \mathrm{~m} / \mathrm{s}$ of average wind speed (European Wind Energy Association, 2009) that is quite common in the Russian territory according to the Global Average Wind Speed Map (Vaisala 3TIER, 2014). The normative capacity factor of $14 \%$ that set for solar power stations, is achievable with solar irradiation at the level of about $1500 \mathrm{kWh} / \mathrm{m}^{2}$ per year $(\mathrm{ABB}, 2010)$, which corresponds to the irradiation in the areas of Southern Russia (Breyer and Schmid, 2010). The normative capacity factor set for hydro power approximately equals the capacity factor of small hydro plants operating in average flow conditions defined for the UK, on the level of $40 \%$ (British Hydropower Association, 2012). A detailed presentation of the RE capacity price calculation is presented in Appendix 2.

\section{Numerical comparative study of the new Russian RE investment incentive policy}

Policy influence on investors' behavior may be analyzed in different ways, one of the ways is numerical analysis that has been found to be a good way to corroborate and complete the findings of policy-desk type reviews (Azuela and Barroso, 2012). When numerical analysis is used, it can be done, e.g., by defining the key influential factors affecting the project and assessing their impact on the economic viability of the project. Here, we analyze the profitability of investments into the three different RE types that are covered by the Russian RE support mechanism with a model built for the purpose and also run a sensitivity analysis in order to see, how the profitability of a RE investment project changes, when the values of identified key factors change from $-50 \%$ to $+50 \%$ starting from a selected start-value. 
For the purposes of comparative analysis between RE support schemes, we have calculated the sensitivity of a profitability of a model RE investment project to selected variables'values, when it is supported by the Russian RE capacity mechanism, and as a benchmark, when the same model project is supported by generic feed-in premium support mechanism. The feed-in premium scheme is chosen as a benchmark due to its simplicity, popularity in emerging markets, and because it was an initial choice also of the Russian government, even if such a policy never saw the light of day in Russia (International Finance Corporation, 2013). A feed-in premium level that gives an "equal to the RE capacity mechanism profitability" is used as a base level benchmark. In the construction of the model project, a number of choices with regards to the values used had to be made, but the same chosen values were consistently used in both the compared cases. The calculations were performed with MS Excel. The investment profitability analysis model used is presented in detail in (Kozlova, 2015).

\subsection{Modeling assumptions}

Electricity prices used in the analysis are the average day-ahead market prices, derived from the Russian Automated Information Data System on Electricity and Capacity Markets (NP Market Council, 2015). The capacity price calculation was made in accordance with the rules provided by the Russian legislation (Government of Russian Federation, 2013b; Government of Russian Federation, 2013a; Government of Russian Federation, 2015) and described above for all the three RE technologies. The aim is to analyze an "average" investment project, rather than a project located in a particular price zone (area in Russia). For this reason the nodal electricity price forecast for the capacity payment calculation is substituted by the average Russian day-ahead electricity market price. Data on the Russian 10-year government bond yield is used as the risk free rate and was obtained from Investing.com. Russian consumer price index data was procured from the Russian Federal State Statistics Service (Federal State Statistics Service, 2015). Values for the above three variables were, for the purposes of this illustration, projected until 2036 by using linear regression. The planned CAPEX is assumed to be at the limit level for each technology type for the commissioning year 2017, see Appendix 2, Table IV. The property tax expenses were defined based on 
the calculated project cash-flows and in accordance with the Russian Tax Code.

The model investment has a total installed capacity of $10 \mathrm{MW}$. The CAPEX used in the model is divided into two phases. The first phase, project development, takes place in 2015 and accounts for 5\% of the investment cost and the second phase, construction, takes place in 2016 and accounts for $95 \%$ of the investment cost (UNEP and Aequero, 2011). For simplicity, production start is assumed to be on 01.01.2017 and the project lifetime is set at 20 years after the two-year investment phase. In this illustrative example we do not consider possible delays on project starts, such that have been evident, e.g., in association with many wind-power investments in Europe.

The capacity factors used for the three RE technologies are according to the fixed norm discussed above. The OPEX used is at the norm level, see (Government of Russian Federation, 2013a), and adjusted by the consumer price index change projections for each year. Taxes are calculated in accordance with the Russian Tax Code, the income tax rate is assumed to remain at $20 \%$, the property tax rate used is $2.2 \%$, and a straight-line depreciation for the whole project life-time is assumed.

The discount rate used was defined based on the data available from the Datastream service for several of the largest Russian energy companies, namely Inter RAO, OGK 2 owned by Gazprom, E.ON, Enel, and RusHydro that together with the state-owned non-listed RosAtom own more than half of all the electricity production capacity in the country. Their weighted average cost of equity is estimated to be at the level of $15,7 \%$, the cost of debt at $9,5 \%$, and the debt ratio at $40,5 \%$, resulting in a total weighted average cost of capital equal to an estimated $12,4 \%$. The discount rate is assumed to remain constant.

\subsection{Results from the capacity price calculation}

The results of the capacity price calculation, in accordance with the legislative rules and assumptions discussed above, show essential differences across the three technology types. As the RE capacity price 
calculation is based on the project expenses and on the expected production levels, the inherent discrepancy in technological features across the different technology types causes differences in the required return to cover the investment costs, and subsequently causes differences in the capacity prices. The RE capacity price calculation results with details are presented in Table I.

TABLE I: RE CAPACITY PRICE CALCULATION FOR THE YEAR 2017 FOR ALL THREE RE TYPES

\begin{tabular}{|c|l|r|r|r|}
\hline$\#$ & \multicolumn{1}{|c|}{ Parameter } & Wind & Solar & Hydro \\
\hline 1 & Normative capacity factor & $27 \%$ & $14 \%$ & $38 \%$ \\
\hline 2 & CAPEX, thous. rub./kW & 109.8 & 109.6 & 146.0 \\
\hline 3 & OPEX, rub./kW month & 161 & 233 & 137 \\
\hline 4 & Property tax expenses, rub./kW year & 1,392 & 2,318 & 3,132 \\
\hline 5 & $\begin{array}{l}\text { Forecasting profit from electricity sales, } \\
\text { rub./kW year }\end{array}$ & 2,355 & 2,351 & 4,405 \\
\hline 6 & Gross required revenues, rub./kW year & 23,729 & 24,546 & 30,629 \\
\hline 7 & Share of costs needed to be covered & $86 \%$ & $93 \%$ & $85 \%$ \\
\hline 8 & RE capacity price rub./kW month & 1,728 & 2,081 & 2,202 \\
\hline $\mathbf{9}$ & RE capacity price rub./kW year & $\mathbf{2 0 , 7 4 2}$ & $\mathbf{2 4 , 9 7 8}$ & $\mathbf{2 6 , 4 2 3}$ \\
\hline 10 & RE capacity price converted to rub./kWh & 8.8 & 20.4 & 7.9 \\
\hline
\end{tabular}

Table I shows that all three technologies require a substantial share of costs to be covered by the support mechanism to be profitable. The "share of costs to be covered" is the share that will be covered by the RE capacity remuneration by the RE capacity mechanism, while the remaining share will come from electricity sales. For example, a solar power project that has the same CAPEX level as a wind power plant will receive less revenues from electricity sales due to its lower capacity factor. In comparison to small hydro, solar power requires roughly $25 \%$ less capital costs per MW, but the capacity factor is more than halved, leaving solar technology as the most expensive among the three technologies in terms of electricity production cost that is indicated in terms of the RE capacity price converted into rub./kWh. This means that solar power is the most expensive production alternative in relative terms, however, the situation may change over time, see, e.g., (Benson and Magee, 2014).

\subsection{Sensitivity analysis of RE investment profitability under two different support mechanisms}

To further study the capacity mechanism for RE investments, we analyze the sensitivity of the model project profitability to a number of contributing factors and compare the results with the results received, ceteris paribus, under a generic feed-in premium scheme. We found that the three technologies are very 
similar in terms of the sensitivity of profitability to the contributing factors. Minor differences are however found and they are associated with initial differences in capital costs, capacity factors, and other technology-specific features. For the purposes of this illustration we only show the case of a wind power project and use it as the basis for examining the differences between the sensitivity of the profitability under the two different RE support mechanisms. The results of the sensitivity analysis are presented in Figure 1 for the generic feed-in premium case (the left graph) and for the Russian RE capacity mechanism (the right graph).
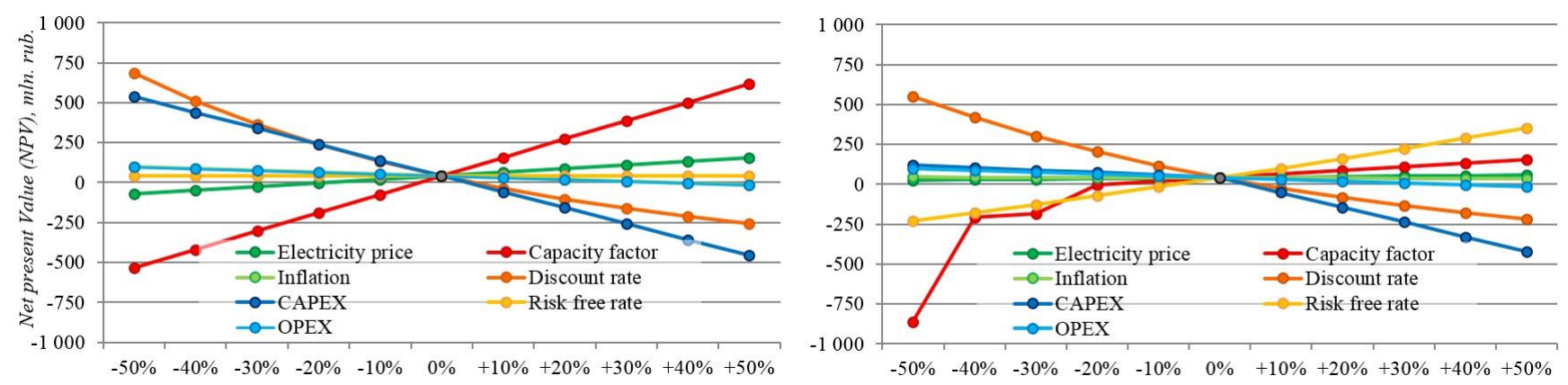

Figure 1. Model project NPV sensitivity to selected factors' values under a feed-in premium scheme (left) and the Russian RE capacity mechanism (right).

Visual inspection reveals that generally speaking the project profitability under the Russian RE capacity mechanism seems to be less sensitive to the contributing factors, than under the generic feed-in premium scheme. A notable exception is the case, where the RE capacity factor falls below the threshold that fully cuts out the incentive payments. Table II summarizes the sensitivity analysis results.

TABLE II: SENSITIVITY OF PROJECT NPV TO SELECTED FACTORS' ${ }^{\prime}$ VALUES

\begin{tabular}{|l|l|l|}
\hline Factor & Under the feed-in premium & Under the capacity mechanism \\
\hline Electricity price & Moderate sensitivity. & Compensation effect causes very low sensitivity. \\
\hline Inflation (CPI) & Low sensitivity. & Compensation effect causes very low sensitivity. \\
\hline Risk free rate & No sensitivity. & $\begin{array}{l}\text { NPV becomes sensitive to the risk free rate, due to } \\
\text { the fixed discount rate. }\end{array}$ \\
\hline CAPEX & $\begin{array}{l}\text { High sensitivity - linear } \\
\text { relationship. }\end{array}$ & $\begin{array}{l}\text { Sensitivity to CAPEX changes according to the } \\
\text { amount of CAPEX, potential from savings } \\
\text { muffled. }\end{array}$ \\
\hline $\begin{array}{l}\text { RE capacity } \\
\text { factor }\end{array}$ & $\begin{array}{l}\text { High sensitivity - linear } \\
\text { relationship. }\end{array}$ & $\begin{array}{l}\text { Target RE capacity factor and the two thresholds } \\
\text { cause the sensitivity to change stepwise. }\end{array}$ \\
\hline OPEX & Low-to-moderate sensitivity. & Low-to-moderate sensitivity. \\
\hline Discount rate & High sensitivity. & High sensitivity. \\
\hline
\end{tabular}


Under the Russian RE capacity mechanism, project profitability is less sensitive to electricity price and to changes in the inflation, though changes in the CPI seem to have a moderate effect on profitability under both incentive systems. Changing the risk-free rate has an effect under the Russian RE capacity mechanism, as the RE capacity payments depend on the level of the risk-free rate. Respectively, there is no effect under the feed-in premium that is, profitability is insensitive to changes in the risk-free rate under the feed-in premium scheme. It needs to be noted that project-specific debt-levels play a role here, as in reality the risk-free rate is often connected to the cost of debt. In broad strokes, "external" factors' influence on the project profitability is low for both cases - this is expected, as it is the main idea behind these RE incentive systems.

Project-related "internal" factors play a significant role for project profitability under both mechanisms. It is natural that when capital costs increase project profitability suffers. The capacity factor, or in other words the amount of energy produced of the total production capacity, is directly (linear relationship) affecting the feed-in premium case, and both, directly and in-directly through the load coefficient used in the capacity price calculation affecting the capacity mechanism case - capacity mechanism puts a "tougher incentive" in place for producing electricity.

Operational costs have a direct and a clear relationship of the same size to profitability in both cases, the better the project can manage the operational costs, the better is the profitability. For both cases the sensitivity of project profitability to the discount rate is considerable, and accentuated by the long project lifetime - what is interesting and important to notice is that the RE incentive schemes actually work to reduce the discount rate and therefore, also in this way, incentivize investment into RE production.

Falling outside Figure 1, but tested with the investment model the "local content" factor, if not fulfilled, substantially reduces capacity payments for the whole contract term, making RE investment under the capacity mechanism irreversibly sunk. 


\section{First results of the Russian RE capacity mechanism implementation}

So far, three RE power generation project auctions have been conducted since the year 2013. The auction has been open for projects commissioned in a four-year ahead window after the year of auction, e.g., in 2013 projects were selected with starting dates for the years 2014-2017. Table III summarizes results of all three auctions and presents both the target and the amount of selected to-be-installed capacity.

TABLE III: Auction results, MW (auctions 2013-2015)

\begin{tabular}{|l|l|l|l|l|l|l|l|}
\hline Technology & Capacity & 2014 & 2015 & 2016 & 2017 & 2018 & 2019 \\
\hline \multirow{4}{*}{ Wind } & target & 100 & 250 & 250 & 500 & 750 & 750 \\
\cline { 2 - 8 } & selected & 0 & 51 & 50 & 90 & 0 & 0 \\
\cline { 2 - 8 } & $\%$ & $0 \%$ & $20 \%$ & $20 \%$ & $18 \%$ & $0 \%$ & $0 \%$ \\
\hline \multirow{5}{*}{ Solar PV } & target & 120 & 140 & 200 & 250 & 270 & 270 \\
\cline { 2 - 8 } & selected & 35,2 & 140 & 199 & 255 & 285 & 270 \\
\cline { 2 - 8 } & $\%$ & $29 \%$ & $100 \%$ & $100 \%$ & $102 \%$ & $106 \%$ & $100 \%$ \\
\hline \multirow{3}{*}{ Small hydro } & target & 18 & 26 & 124 & 124 & 141 & 159 \\
\cline { 2 - 8 } & selected & 0 & 0 & 0 & 20,64 & 0 & 49,8 \\
\cline { 2 - 8 } & $\%$ & $0 \%$ & $0 \%$ & $0 \%$ & $17 \%$ & $0 \%$ & $31 \%$ \\
\hline
\end{tabular}

The auction results reveal that the RE capacity mechanism seems to be working well for solar PV investments, with the full volume of target capacity selected and competition in place. In contrast, wind and small hydro power investors seemingly face some barriers and are reluctant to participate. There may be several reasons behind this situation.

Poor results of the first auction, especially for the first year 2014, may be explained by a too short period (a couple of months) between the policy introduction and the deadline for bid submission. Investors simply were not able to prepare all the required documentation. For 2014 and 2015 the observed shortage of wind and small hydro power bids is attributable to the strict localization requirements and the capital cost limits. In addition, the devaluation of the ruble has made it more difficult to meet the capital cost limit calculated in rubles for technologies that are more dependent on imports payable in foreign exchange. Projects have most likely been unable to switch to Russian national manufacturers, simply due to their scarcity. Investors could not meet the RE capacity mechanism requirements of localization and invoked 
Russian government to revise the rules. As the result of negotiations between investors and policymakers, amendments to the RE capacity mechanism were introduced right before the third auction in November 2015 (Government of Russian Federation, 2015).

The said amendments include several important changes, designed to remove the above mentioned barriers to investment. Localization requirement and capital cost limit have been "softened" for wind power projects. RE capacity remuneration for small hydro power investment is increased by introducing an additional coefficient, see Appendix 2, while the localization requirement and the CAPEX limits remain on the same level as previously for this technology. To resolve the issue with currency volatility, the correction of the capital costs limit (as well as project-specific planned CAPEX) is introduced and takes into account ruble value movements for the 'foreign' part of the CAPEX, during the investment phase. Together with the development of the Russian national RE manufacturing sector, these changes are expected to resolve the current problems.

\section{Conclusion and Policy Implications}

Enacted in 2013, the Russian renewable energy support mechanism is based on capacity remuneration and thus has a different starting point for a RE investment incentive mechanism than the commonly used incentive systems for renewable energy used. The RE capacity mechanism combines a "guarantee" of a set level of return on investment for RE power generation investments, shielding their profitability from changing market factors, while including a number of codified requirements on electricity production, local content, and on capital expenditure.

The studied RE capacity mechanism represents the first supporting policy for renewable energy put in action in Russia. Being an extension of the pre-existing capacity market rules, the RE support mechanism has been naturally embedded into the existing Russian energy market system. On one hand it is an easy-to-implement solution for policymakers, and on the other a not fully unfamiliar scheme for the 
existing market participants. What can be said is that the RE capacity pricing under the mechanism is rather complex and one that requires expertise in understanding the effects it has on investment profitability. This paper has "opened up" the complexity of the mechanism and of the RE capacity pricing.

$\mathrm{RE}$ remuneration is paid as capacity price to selected projects within the framework of long-term contracts. The capacity price is updated on a regular basis within each agreement to reflect the changing market environment and the performance of the project, in accordance with the set procedures. The RE mechanism is designed to make RE project profitability rather independent from project external factors, such as market prices for electricity, inflation, and interest rates. Our analysis shows that it can be said to perform rather well in that respect. Project internal factors, such as capital costs, operating costs, and the RE capacity factor remain un-hedged by the mechanism. The mechanism restricts project capital costs to control the overall burden on the market system, imposes localization requirement to push the Russian national manufacturing sector, and penalizes for low levels of electricity production. Our illustrative numerical analysis and the connected sensitivity analysis on a model investment show that the different requirements set by the mechanism are important from the point of view of RE project profitability. Especially, what is found is that project underperformance, reflected as low electricity production, capital costs overspending, and failing the localization requirement is the most important single issue to consider with regards to the mechanism, when RE investments are planned.

The capacity remuneration grows with growing interest rates on the market, allowing investors to sustain higher financing costs. This effect provides investors with considerable risk reduction that is not offered by any other RE supporting policy type, however the adjustability of the capacity price prevents investors from fully benefiting from very favorable market conditions and thus shields the capacity buyers.

The complexity of the RE mechanism, including the high level of controllability of the policy puts a heavy responsibility on the policymakers and policy controllers to estimate the used values in a way that 
creates a favorable market environment for investment. A too loose set of requirements may decrease the policy cost-efficiency, while a too strict set may work to hinder investments, as already has been learned from the experience with wind and small hydro power.

In an international and an emerging economies context the Russian RE capacity mechanism takes a special place among the existing RE policy types. It is clearly different from the three main types of RE support mechanisms used in emerging economies. The results from the first three implemented project auctions show that the mechanism has been a partial success. It remains to be seen, if the enacted changes boost investment into RE in Russia also within the wind power and small hydropower technologies.

As a final note on policy flexibility, in terms of the Russian RE support mechanism, it can be observed that as each supported project is a specific case and represented by a specific contract, changing any or all aspects of the national level support for renewable energy production in Russia is not conditioned in any way by the existing policy. Each contracted project is singular and can co-exist with any kind of new system irrespective of its provisions. This means that migration away from the existing mechanism is "easy" as it is not likely to cause resistance by the existing support contract holders.

Future research on the topic will include using simulation-based techniques to deepen the investment analysis. More detailed "real world" and area specific analysis is also something that will benefit the industry. Comparative analysis of the Russian capacity mechanism with a broader set of existing and in detail modeled RE policies worldwide will benefit policymakers. It will also make sense to broaden the research scope to include the newly introduced Russian renewable energy premiums scheme for retail markets that focuses on medium-scale RE projects.

\section{Acknowledgment}

The authors would like to acknowledge the support received by M. Kozlova from the Fortum Foundation. The financing has not included any involvement by the sponsor in the research process. 


\section{References}

ABB, 2010. Technical Application Papers No.10 Photovoltaic Plants. Available at: http://www04.abb.com/global/seitp/seitp202.nsf/c71c66c1f02e6575c125711f004660e6/d54672ac6e97a 439c12577ce003d8d84/\$file/vol.10.pdf [October 6, 2015].

Apergis, N., Payne, J.E., 2011. The renewable energy consumption-growth nexus in Central America. Applied Energy, 88, 343-347.

Apergis, N., Payne, J.E., 2010. Renewable energy consumption and growth in Eurasia. Energy Economics, 32, 1392-1397.

Azuela, G.E., Barroso, L.A., 2012. Design and performance of policy instruments to promote the development of renewable energy: emerging experience in selected developing countries, World Bank Publications,.

Beck, F., Martinot, E., 2004. Renewable energy policies and barriers. Encyclopedia of energy, 5, 365-383.

Benson, C.L., Magee, C.L., 2014. On improvement rates for renewable energy technologies: Solar PV, wind turbines, capacitors, and batteries. Renewable Energy, 68, 745-751.

Boute, A., 2016. Off-grid renewable energy in remote Arctic areas: An analysis of the Russian Far East. Renewable and Sustainable Energy Reviews, 59, 1029-1037.

Boute, A., 2015. Russian Electricity and Energy Investment Law.

Boute, A., 2013. Renewable Energy Federalism in Russia: Regions as New Actors for the Promotion of Clean Energy. Journal of environmental law, eqt005.

Boute, A., 2012. Promoting renewable energy through capacity markets: An analysis of the Russian support scheme. Energy Policy, 46, 68-77.

Breyer, C., Schmid, J., 2010. Population Density and Area weighted Solar Irradiation: global Overview on Solar Resource Conditions for fixed tilted, 1-axis and 2-axes PV Systems. Horizon, 4444444, 1.

British Hydropower Association, 2012. A Guide to UK Mini-Hydro Developments Plants. Available at: http://www.british-hydro.org/Useful_Information/A\%20Guide\%20to\%20UK\%20mini-hydro\%20devel opment\%20v3.pdf [October 6, 2015].

Central Intelligence Agency, 2014. The World Factbook. Country Comparison. Electricity production. Available at: https://www.cia.gov/library/publications/the-world-factbook/rankorder/2232rank.html [October 6, 2015].

del Río, P., Cerdá, E., 2014. The policy implications of the different interpretations of the cost-effectiveness of renewable electricity support. Energy Policy, 64, 364-372.

del Río, P., Linares, P., 2014. Back to the future? Rethinking auctions for renewable electricity support. Renewable and Sustainable Energy Reviews, 35, 42-56. 
European Wind Energy Association, 2009. Wind Energy the Facts. Technology. Available at: http://www.wind-energy-the-facts.org/images/chapter1.pdf [October 6, 2015].

Fais, B., Blesl, M., Fahl, U., Voß, A., 2014. Comparing different support schemes for renewable electricity in the scope of an energy systems analysis. Applied Energy, 131, 479-489.

Federal State Statistics Service, 2015. Consumer Price Index (Available only in Russian). Available at: http://www.gks.ru/free_doc/new_site/prices/potr/tab-potr1.htm [October 6, 2015].

Frankfurt School UNEP Collaborating Centre, Bloomberg New Energy Finance, 2015. Global Trends in Renewable Energy Investment 2015.

Gore, O., Viljainen, S., 2014. Challenges of cross-border trade between two markets with different designs, In: European Energy Market (EEM), 2014 11th International Conference on the, Anonymous IEEE, pp. 1-5.

Gore, O., Viljainen, S., Makkonen, M., Kuleshov, D., 2012. Russian electricity market reform: Deregulation or re-regulation? Energy Policy, 41, 676-685.

Government of Russian Federation, 2015. 10 November 2015 Decree \#1210 on the introduction of amendments to the certain legislative acts regarding the use of renewable energy sources in the wholesale electricity and capacity market.

Government of Russian Federation, 2013a. 28 May 2013 Decree \#449 on the mechanism of promoting the use of renewable energy in the wholesale market of electric energy and power.

Government of Russian Federation, 2013b. 28 May 2013 Resolution \#861-r on amendments being made to Resolution \#1-r 8.01.2009 on the main directions for the state policy to improve the energy efficiency of the electricity sector on the basis of renewable energy sources for the period up to 2020.

Government of the Russian Federation, 2010a. 13 April 2010 Decree No.238 on the Determination of Price Parameters for the Trade in Capacity.

Government of the Russian Federation, 2010b. 27 December 2010 Decree No.1172 Approving the Wholesale Market Rules.

Held, C., Voss, J.O., 2013. Legal Limits for Electricity Capacity Markets in the EU and Germany. Renewable Energy Law and Policy Review, 4, 245-253.

Hobbs, B.F., Hu, M., Iñón, J.G., Stoft, S.E., Bhavaraju, M.P., 2007. A dynamic analysis of a demand curve-based capacity market proposal: the PJM reliability pricing model. Power Systems, IEEE Transactions on, 22, 3-14.

International Energy Agency, International Renewable Energy Agency, 2014. IEA/IRENA Global Renewable Energy Policies and Measures Database. Available at: http://www.iea.org/policiesandmeasures/renewableenergy/ [October 6, 2015].

International Finance Corporation, 2013. Russia's New Capacity-based Renewable Energy Support Scheme. An Analysis of Decree No. 449. Available at: http://www.ifc.org/wps/wcm/connect/f818b00042a762138b17af0dc33b630b/Energy-Suppor-Scheme-E ng.pdf?MOD=AJPERES [October 6, 2015]. 
International Finance Corporation, 2011. Renewable Energy Policy in Russia: Waking the Green Giant. Available at:

http://www.ifc.org/wps/wcm/connect/6239e00040c80fcdb865bd5d948a4a50/Green+Giant_Eng.pdf?M OD=AJPERES [September 2, 2015].

Kozlova, M., 2015. Analyzing the effects of the new renewable energy policy in Russia on investments into wind, solar and small hydro power, Master's thesis ed. Lappeenranta University of Technology, Lappeenranta, Finland, pp. 104.

Kuleshov, D., Viljainen, S., Annala, S., Gore, O., 2012. Russian electricity sector reform: Challenges to retail competition. Utilities Policy, 23, 40-49.

Lund, P.D., 2007. Effectiveness of policy measures in transforming the energy system. Energy Policy, 35, 627-639.

Martinot, E., 1999. Renewable energy in Russia: markets, development and technology transfer. Renewable and Sustainable Energy Reviews, 3, 49-75.

Martinot, E., 1998. Energy efficiency and renewable energy in Russia: Transaction barriers, market intermediation, and capacity building. Energy Policy, 26, 905-915.

Maurer, L.T.A., Barroso, L.A., 2011. Electricity Auctions. An Overview of Efficient Practices. Available at:

http://www.ifc.org/wps/wcm/connect/8a92fa004aabaa73977bd79e0dc67fc6/Electricity+and+Demand+ Side+Auctions.pdf?MOD=AJPERES [October 6, 2015].

NP Market Council, 2015. Automated Information Data System on Electricity and Capacity Markets (Available only in Russian). Available at:

http://www.ais.np-sr.ru/information/IASE_0V_R0_CONSUMPTION\#прогноз_цен_PPЭ [October 6, 2015].

NP Market Council, 2013. 16 December 2013 Proceedings on the introduction of amendments to the Contract of joining the trading system of the wholesale market.

NP Market Council, 2012. Wholesale market. Available at:

http://www.en.np-sr.ru/abouttheelectricityindustry/electricityandcapacitymarkets/wholesalemarket/\#3 [March 12, 2016].

Pegels, A., 2010. Renewable energy in South Africa: Potentials, barriers and options for support. Energy Policy, 38, 4945-4954.

REN21, 2015. Renewables 2015 Global Status Report. Available at: http://www.ren21.net/wp-content/uploads/2015/07/REN12-GSR2015_Onlinebook_low1.pdf [August $15,2015]$.

Russian Ministry of Energy, 2013. Power Industry Basic Indicators (available only in Russian). Available at: http://www.minenergo.gov.ru/activity/powerindustry/basic_indicators/ [October 6, 2015].

Salim, R.A., Rafiq, S., 2012. Why do some emerging economies proactively accelerate the adoption of renewable energy? Energy Economics, 34, 1051-1057.

Tennbakk, B., Lafitte, J.-., Capros, P., Delkis, C., Tasios, N., Zabara, M., et al., 2013. Capacity Mechanisms in Individual Markets within the IEM. Available at: 
https://ec.europa.eu/energy/sites/ener/files/documents/20130207_generation_adequacy_study.pdf [October 6, 2015].

The Ministry of Economic Development and Trade, 2010. 26 July 2010 Order No. 329.

Timilsina, G.R., Kurdgelashvili, L., Narbel, P.A., 2012. Solar energy: Markets, economics and policies. Renewable and Sustainable Energy Reviews, 16, 449-465.

UNEP, Aequero, 2011. Catalysing Early Stage Investment. Addressing the Lack of Early-Stage Capital for Low-Carbon Infrastructure in Developing Economies. Available at: http://www.scaf-energy.org/news/pdf/Catalyzing\%20Early\%20Stage\%20Investment.pdf [October 6, 2015].

Vaisala 3TIER, 2014. Global Mean Wind Speed at 80m. Available at:

http://www.vaisala.com/VaisalaImages/ERG/Vaisala_global_wind_map.pdf [October 6, 2015].

Vasileva, E., Viljainen, S., Sulamaa, P., Kuleshov, D., 2015. RES support in Russia: Impact on capacity and electricity market prices. Renewable Energy, 76, 82-90.

Zhang, H., Li, L., Cao, J., Zhao, M., Wu, Q., 2011. Comparison of renewable energy policy evolution among the BRICs. Renewable and Sustainable Energy Reviews, 15, 4904-4909. 


\section{APPENDIX 1. CAPACITY PRICE CALCULATION FOR CONVENTIONAL ENERGY}

Step 1. A "guaranteed rate of return" is calculated, based on an initially set level of $14-15 \%$ (for different groups of participants) and corrected for changes in a reference risk-free rate, for which the yield of the Russian state long-term obligations is used as the reference (only notes with maturities from 8 to 10 years are appropriate for the calculation, see (The Ministry of Economic Development and Trade, 2010)). The following formula is used:

$$
R_{i}=\frac{\left(1+R_{b}\right) *\left(1+R f_{i}\right)}{\left(1+R f_{b}\right)}-1 \approx R_{b}+\Delta R f
$$

where $R_{i}$ is the guaranteed rate of return for $i$ year (from 1 to 15 );

$R_{b}$ is base guaranteed rate of return $(=14-15 \%)$;

$R f_{b}$ is base risk free rate $=8.5 \%$;

$R f_{i}$ is risk free rate for $i$ year (inflation correction).

The guaranteed rate of return is effectively a minimum, or a "floor rate" established for the return of these investments and is paid, if other factors such as capital and operating costs are within set norms.

Step 2. As power investment projects receive revenues also from electricity sales, the share of the costs to be covered by the capacity payments, the "expense share", is separately established. The expense share is based on the expected revenues from the electricity market that are dependent on the electricity production profile of the investment. Furthermore, it is a function of the capital (CAPEX) and the operational expenditures (OPEX). The values of the inputs to the expense share calculation are specified and remain fixed for all producers (Government of the Russian Federation, 2010a). To avoid the capacity price being out of date with market conditions, the OPEX value is adjusted by inflation for each year of the contract, and the expense share is adjusted for electricity price changes twice during the contract 
duration (on the $4^{\text {th }}$ and the $7^{\text {th }}$ year of the contract).

Step 3. A "capacity price component" is calculated. This includes first arriving at an "adjusted CAPEX" for the first year of the capacity contract:

$$
C A P E X_{a d j}=C A P E X * E *\left(1+R_{-1}\right)^{N_{s t}}
$$

where CAPEX is defined separately for each technology type, and multiplied by a number of fixed coefficients, see (Government of the Russian Federation, 2010a) and where

$E$ is the expense share defined in step 2;

$R_{-1}$ is $R$ defined in (1) for $i=-1$;

$N_{s t}$ is a constant; specified for each technology type separately;

Then the adjusted CAPEX is converted to annual payments with a variable interest rate. The payback period is assumed to be 15 years and thus capacity price is calculated for 15 years. However, since the contract duration is set at 10 years, the capacity price calculated for years $11-15$ is settled within the last three years of the ten year capacity contract. We remark that this is a point of discussion in Russia and the contract term may in the future be extended to fifteen years. The payment of the principal and the remaining principal are defined as (principal implies adjusted CAPEX):

$$
\begin{gathered}
P p_{i}=\frac{R p_{i} *(k-1)}{\left(k^{16-1}-1\right)}, \\
R p_{i}=R p_{i-1}-P p_{i-1}+\left(R_{i-1}-R_{i-2}\right) *\left(1+R_{i-1}\right) * R p_{i-1},
\end{gathered}
$$

where $P p_{i}$ is the annual principal payment;

$R p_{i}$ is the remaining principal (for $i=1 R p_{1}=C A P E X_{a d j}$ ); 
$k$ is equal to 1.19 for the first price zone and 1.16 for the second price zone.

Finally, the capacity price component is defined as a percentage of the remaining principal (adjusted on the income tax rate), plus the principal payment itself, and plus the operating expenses:

$$
C P_{\text {comp }}=R p_{i} * \frac{R_{i-1}}{1-r_{\text {inc } c_{\text {tax }}}}+P p_{i}+O P E X * E,
$$

where $C P_{\text {comp }}$ is the capacity price component;

$R p$ is a result from (4);

$r_{\text {inctax }}$ is an income tax rate equal to 0.2 (or $20 \%$ );

$P p$ is a result from (3);

$O P E X$ is an inflation adjusted $O P E X$, specified in (Government of the Russian Federation, 2010a) separately for each technology type;

$E$ is expense share defined in step 2.

Step 4 . The capacity price is derived as the sum of the capacity price component, $C P_{\text {comp }}$, and property tax expense multiplied by the expense share:

$$
C P=C P_{\text {comp }}+T_{p r} * E,
$$

where $C P$ is capacity price;

$C P_{\text {comp }}$ is defined in (5);

$T_{p r}$ is the average property tax expenses,

$E$ is the expense share defined in step 2; 
Step 1. Defining rate of return with the same formula (1) with the only difference, that basic return is set as $14 \%$ for project that for auctioned before 2016 and $12 \%$ for the rest.

Step 2. The expense share to be covered is determined for the "average RE power generator" each year of the capacity contract tenor. Preliminary expense share is calculated using the following formula:

$$
\begin{gathered}
E_{0_{i}}=\frac{R e_{i}}{12 * R c_{i}}, \\
E_{1_{i}}=\left\{\begin{array}{c}
0, \text { if } E_{0_{i}} \geq 1 \\
1-E_{0_{i}}, \text { if } 0>E_{0_{i}}>1 \\
1, \text { if } E_{0_{i}} \leq 0
\end{array}\right.
\end{gathered}
$$

where $E_{0_{i}}$ is the ratio of expected revenues from electricity sales / required revenues to cover all costs; $E_{1_{i}}$ the preliminary expense share;

$R e$ is the expected revenue from the electricity sales;

$R c$ is the expected revenue from the capacity sales.

The above means that if the electricity price received from the market is high enough to cover the minimum guaranteed return for RE power generation investments, the paid incentive capacity price is zero. In reality the situation is hypothetical at best.

To determine the final expense share value $E$ for each year of the agreement, the average of the actual and the following year's preliminary expense share (8) is calculated. The expense share for uneven years of the contract duration is set to be equal to this average, and for even years to the value calculated for the previous year. 
The expected revenue from capacity sales, for the purpose of expense share calculation, is determined in accordance with the third (next) step of the calculation process with the following assumptions: expense share $(E)$ is equal to 1 and the capital expenditures (CAPEX) are defined as the weighted average of CAPEX of the bids submitted to the capacity price auction (separately for each technology). In other words, step 3 is actually repeated twice: once for the 'average project', to calculate the expense share, and once to calculate the actual capacity price for a specific project.

The revenue from the electricity sales calculation is done as follows:

$$
R e_{i}=c f_{i} * \text { hours } *\left(\frac{P_{i}}{k}-C_{p r_{i}}\right)
$$

where $c f$ is a normative capacity factor (Table VII);

hours is a quantity of hours in a year $\mathrm{i}$;

$P$ is a day-ahead electricity market price defined in (10);

$k$ is a coefficient of power consumption for own needs that is 1.005 for all RE types;

$C_{p r}$ is inflated variable cost of production initially defined for wind, solar, and hydro as 1,1 , and 10 $\mathrm{rub} / \mathrm{MWh}$ respectively;

The day-ahead electricity price is forecasted as a weighted average of the previous years' prices of all nodes, corrected with a growth rate. The following formula is used:

$$
P_{i}=\frac{\sum_{h} \sum_{q} P_{q, h} * \operatorname{Prod}_{q, h}}{\sum_{h} \sum_{q} \operatorname{Prod}_{q, h}} * \prod_{Y=X}^{i} g_{Y}^{C},
$$

where $h$ is an hour of previous year;

$q$ is a node; 
$P_{q, h}$ is the day ahead electricity price for a particular node and hour (time);

$\operatorname{Prod}_{q, h}$ is the production volume for a particular node and an hour;

$\mathrm{g}^{\mathrm{C}} \mathrm{Y}$ is a forecasted growth rate of prices of gas (for the first price zone) or of coal (for the second price zone) for year Y;

Step 3. Calculating the capacity price component for RE has a similar logic to the "same" calculation for conventional energy, but with some important differences. Firstly, capital expenditure level is not fixed, but the limit is set separately for each technology and for each year, and the set values decrease with time, see (Government of Russian Federation, 2013b; Government of Russian Federation, 2013a). Table IV illustrates this issue further.

TABLE IV: CAPEX LIMIT AND OPEX NORM (SET VALUE)

\begin{tabular}{|l|r|r|r|r|r|}
\hline \multirow{2}{*}{ Technology type } & \multicolumn{3}{|c|}{ CAPEX limit, thous. rub./kW } & \multirow{2}{*}{$\begin{array}{c}\text { OPEX norm, } \\
\text { rub./kW pm }\end{array}$} \\
\cline { 2 - 5 } & 2016 & 2017 & 2018 & 2019 & 118 \\
\hline Wind & 109,9 & 109,8 & 109,7 & 109,6 & 170 \\
\hline Solar & 111,8 & 109,6 & 107,4 & 105,3 & 100 \\
\hline Hydro & 146,0 & 146,0 & 146,0 & 146,0 & . \\
\hline
\end{tabular}

RE projects are "capped" with the values in Table IV that is, projects with planned CAPEX higher than the set limits cannot participate in the auction. If the planned CAPEX is lower than the limits given in Table IV the lower figure is used in the calculation of the capacity price. Hence, the lower the planned CAPEX is, the lower is the calculated capacity price, and this causes a clear disincentive to reduce the CAPEX level. To keep the motivation among investors to reduce the CAPEX, the CAPEX is set as the object on which the competing projects ranked on: only a selected number of projects, with the lowest planned CAPEX that satisfy the target selection volume, become eligible for the capacity agreement (incentive system). The target installed capacity for each year is presented in the Table V (Government of Russian Federation, 2013b).

TABLE V: TARGET INSTALLED CAPACITY, MW

\begin{tabular}{|l|r|r|r|r|r|r|r|r|}
\hline $\begin{array}{c}\text { Technology } \\
\text { type }\end{array}$ & 2014 & 2015 & 2016 & 2017 & 2018 & 2019 & 2020 & Total \\
\hline Wind & 100 & 250 & 250 & 500 & 750 & 750 & 1,000 & 3,600 \\
\hline Solar & 120 & 140 & 200 & 250 & 270 & 270 & 270 & 1,520 \\
\hline
\end{tabular}




\begin{tabular}{|l|r|r|r|r|r|r|r|r|}
\hline Hydro & 18 & 26 & 124 & 124 & 141 & 159 & 159 & 751 \\
\hline
\end{tabular}

There are three coefficients that are used in further conditioning the planned CAPEX, when the capacity price calculation is performed. The first and the more important one is the "local content" coefficient that is a requirement of acquiring a set part of the services and equipment used in the investment such that they are produced locally in Russia (Table VI) (Government of Russian Federation, 2013a). The projects with planned localization lower than the set target are rejected.

TABLE VI: LOCAL CONTENT REQUIREMENT

\begin{tabular}{|l|r|r|r|r|r|r|}
\hline \multirow{2}{*}{ Technology type } & \multicolumn{4}{|c|}{ Target local content requirement } & \multicolumn{2}{c|}{ Coefficient } \\
\cline { 2 - 6 } & 2016 & 2017 & 2018 & 2019 & Target achieved & $\begin{array}{c}\text { Target not } \\
\text { achieved }\end{array}$ \\
\hline Wind & $25 \%$ & $40 \%$ & $55 \%$ & $65 \%$ & 1.00 & 0.45 \\
\hline Solar & $70 \%$ & $70 \%$ & $70 \%$ & $70 \%$ & 1.00 & 0.35 \\
\hline Hydro & $45 \%$ & $45 \%$ & $65 \%$ & $65 \%$ & 1.00 & 0.45 \\
\hline
\end{tabular}

The second coefficient reflects changes of the 'foreign' share of capital expenses due to exchange rate movements (Government of Russian Federation, 2015):

$$
k=\operatorname{loc}_{\text {target }}+\left(1-\text { loc }_{\text {target }}\right) * k_{\text {exch.r. }}
$$

where loc $_{\text {target }}$ is target localization percentage,

$k_{\text {exch.r. }}$ is coefficient reflecting ruble value change against US dollar and euro during the investment period (6 months period 12 months prior commercialization date for solar power, 12/18 for wind and 36/42 for hydro). A cap is set $k_{\text {exch.r.MAX }}=3$.

The third coefficient applied to the CAPEX calculation reflects the profits from the wholesale market after the breakeven point, and before the end of the economic life of the project. This coefficient is fixed and equal to 0.90 for wind and hydro power, and 0.99 for solar power.

The CAPEX corrected on exchange rate movements and adjusted with these two coefficients can be calculated as (2) 


$$
C A P E X_{a d j}=C A P E X * E_{1} *\left(1+R_{-1}\right)^{f}
$$

where CAPEX is the planned CAPEX corrected on exchange rate movements and multiplied by the two coefficients;

$E_{1}$ is the expense share, defined in step 2 for the first year of capacity agreement;

$R_{-1}$ is $R$ defined in (1) for $i=-1$;

$N_{s t}$ is a constant that is separately given for each technology type;

$f$ is equal 1 for wind and solar power and 1.5 for hydro (introduced with (Government of Russian Federation, 2015)).

The adjusted CAPEX is converted into annual payments by means of a variable rate annuity similar to the capacity price for conventional energy calculation, but with a small change. The principal payment calculation for the RE investments uses a variable rate of return calculated in equation (1), this is different from using a fixed rate in the conventional energy capacity price calculation, where only the remaining principal is calculated with a variable rate of return.

$$
P p_{i}=\frac{R p_{i} * R_{i-1}}{\left(\left(R_{i-1}+1\right)^{16-1}-1\right)}
$$

where $P p_{i}$ is the principal payment;

$R p_{i}$ is the remaining principal, for $i=1 R p_{1}=C A P E X_{a d j}$.

The remaining principal is calculated exactly in the same way as for conventional energy presented in (4).

The capacity price component is defined as follows: 


$$
C P_{\text {comp }}=\frac{R p_{i} * \frac{R_{i-1}}{1-r_{i n c_{\text {tax }}}}+r P p_{i}}{12}+O P E X * E_{i}
$$

where $C P_{\text {comp }}$ is capacity price component;

$R p_{i}$ is the remaining principal;

$P p_{i}$ is the principal payment;

$R_{i-1}$ is the rate of return defined in (1);

$r_{\text {inctax }}$ is an income tax rate equal to 0.2 ;

$O P E X$ is an inflation adjusted $O P E X$ norm specified in Table IV,

$E_{i}$ is the expense share defined by (7-8).

Step 4. The capacity price for RE investments is defined as the sum of the capacity price component calculated in step 3 and the property tax expenses, multiplied by the expense share defined in step 2:

$$
C P=C P_{\text {comp }}+T_{p r} / 12 * E_{i},
$$

Where $C P$ is the capacity price;

$C P_{\text {comp }}$ is defined in (13);

$T_{p r}$ is the average property tax,

$E_{i}$ is the expense share defined in step 2;

After this, a fixed coefficient of "energy for own needs" equal to 1.005 for all types of RE sources is used to multiply the result.

What still remains is the "load" coefficient. It is a multiplier that is used in the calculation of the capacity price for each year. The load coefficient is in place to ensure the motivation for electricity production and to prevent the 'steel-in the ground' effect, see (Government of Russian Federation, 2013a). See Table VII 
for the load coefficient calculation.

TABLE VII: LOAD COEFFICIENT FORMATION

\begin{tabular}{|l|r|c|r|}
\hline \multicolumn{2}{|c|}{ Normative capacity factor } & \multicolumn{2}{c|}{ Load coefficient formation } \\
\hline Technology type & $\begin{array}{c}\text { Normative capacity } \\
\text { factor }\end{array}$ & Condition ${ }^{1}$ & Load coefficient \\
\hline Wind & $27 \%$ & $\mathrm{~F}<=0.5 \mathrm{~N}$ & 0.0 \\
\hline Solar & $14 \%$ & $0.5 \mathrm{~N}<\mathrm{F}<=0.75 \mathrm{~N}$ & 0.8 \\
\hline Hydro & $38 \%$ & $\mathrm{~F}>0.75 \mathrm{~N}$ & 1.0 \\
\hline
\end{tabular}

An example of how the load coefficient works: if the capacity factor achieved in the previous year for a wind farm was lower than $13.5 \%(=27 \% * 0.5)$, the capacity payments for this year would turn to zero; if capacity factor was between $13.5 \%$ and $20.25 \%(=27 \% * 0.75)$, the capacity payments would be multiplied by 0.8 ; and only if the capacity factor was higher than $20.25 \%$, the capacity payments would be paid in full.

\footnotetext{
${ }^{1} \mathrm{~F}$ is factual average capacity factor achieved in the previous year and $\mathrm{N}$ is normative one.
} 